\title{
Measurement of intragastric pressure: an objective method to ascertain whether gastric wall extension is sufficient for assessment of the non-extension sign*
}

\section{(ㄷ)(우)}

\section{Authors}

Kentaro Imamura', Motoko Machii'², Kenshi Yao', Suketo Sou², Takashi Nagahama ${ }^{3}$, Tsuneyoshi Yao ${ }^{4}$, Takao Kanemitsu' ${ }^{1}$, Masaki Miyaoka' ${ }^{1}$ Kensei Ohtsu' ${ }^{1}$, Toshiharu Ueki ${ }^{5}$

Institutions

1 Department of Endoscopy, Fukuoka University Chikushi Hospital, Chikusino, Japan

2 Department of Gastroenterology, Tobata Kyoritsu Hospital, Kitakyushu, Japan

3 Nagahama Clinic, Fukuoka, Japan

4 Department of Gastroenterology, Sada Hospital, Fukuoka, Japan

5 Department of Gastroenterology, Fukuoka University Chikushi Hospital, Chikusino, Japan

submitted 14.7.2020

accepted after revision 9.12.2020

\section{Bibliography}

Endosc Int Open 2021; 09: E530-E536

DOI 10.1055/a-1352-2761

ISSN 2364-3722

(C) 2021. The Author(s).

This is an open access article published by Thieme under the terms of the Creative Commons Attribution-NonDerivative-NonCommercial License, permitting copying and reproduction so long as the original work is given appropriate credit. Contents may not be used for commercial purposes, or adapted, remixed, transformed or built upon. (https://creativecommons.org/licenses/by-nc-nd/4.0/)

Georg Thieme Verlag KG, Rüdigerstraße 14,

70469 Stuttgart, Germany

Corresponding author Kenshi Yao, MD, PhD, Department of Endoscopy, Fukuoka University Chikushi Hospital, 1-1-1 Zokumyoin, Chikushino City, Fukuoka 818-8502, Japan

Fax: +81-(0)92-929-2630

yao@fukuoka-u.ac.jp

\section{ABSTRACT}

Background and study aims The optimal intragastric pressure (IP) for strong gastric wall extension is unclear. We aimed to develop an accurate method to measure IP using endoscopy and determine the pressure required for strong gastric wall extension.

Methods An in vitro experiment using an endoscope with a rubber attached at its tip was conducted. The process of inserting the pressure measurement probe into the forceps channel was skipped, and the tube of the pressure measurement device was directly connected to the forceps channel. In vivo, the pressure in 51 consecutive patients at the time of strong gastric wall extension was measured. Strong extension of the gastric wall was defined as when the folds in the greater curvature were flattened as a result of sufficient extension of the gastric wall by insufflated air during upper gastrointestinal endoscopy. The IP at that time was measured.

Results In vitro, $20 \mathrm{~mL}$ of tap water was injected once into the forceps channel and then aspirated for 10 seconds. Pressure measurement after irrigation of the forceps channel as well as the measurement by inserting the probe procedure were accurately performed. In vivo, among the 51 included patients, the mean IP (range) was $14.7 \mathrm{mmHg}$ (10-23). Strong extension of the gastric wall was obtained in $96.1 \%$ of patients when the IP was $20 \mathrm{mmHg}$.

Conclusions We developed an accurate method to measure IP using upper gastrointestinal endoscopy. Strong extension of the gastric wall was obtained in almost all patients when the IP was $20 \mathrm{mmHg}$.
* Meeting presentations: Asian Pacific Digestive Week (APDW) 2019 (December 14, 2019)

\section{Introduction}

During upper gastrointestinal endoscopy, the gastric wall can be easily extended by insufflated air. Sufficient extension of the gastric wall is important for endoscopic screening because insufficient extension of the folds in the greater curvature of the gastric corpus can result in blind spots. Conversely, suffi- 


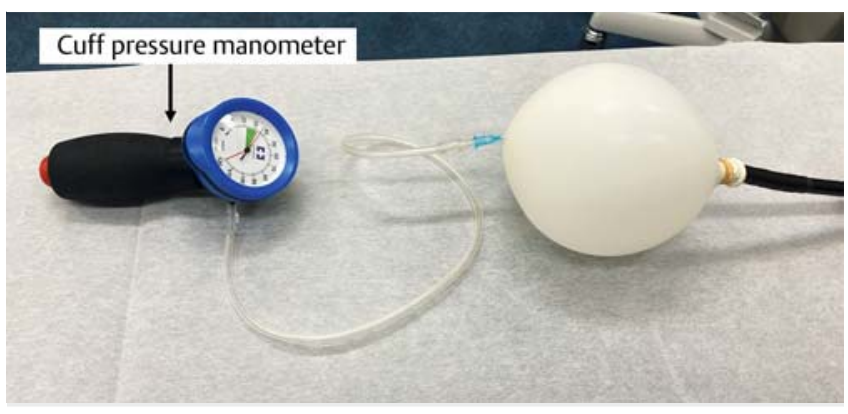

- Fig. 1 Experimental arrangement. A rubber balloon was attached to the tip of the endoscope. The balloon was inflated to certain pressures using a cuff pressure manometer.

cient extension of the gastric wall leads to flattening of the folds in the greater curvature of the gastric corpus and disappearance of blind spots, thus enabling the detection of small and flat lesions [1]. In addition, when performing a preoperative examination, evaluation of the invasion depth of early gastric cancer is crucial to determine the indications for endoscopic treatment. We previously reported that the non-extension sign on endoscopy was useful for the diagnosis of submucosal invasive cancer [2,3]. We also reported that strong extension of the gastric wall is required to assess the presence or absence of the non-extension sign [2,3].

However, the optimal intragastric pressure (IP) for strong extension of the gastric wall is not clear. Therefore, the objectives of this study were to develop an easy and accurate method to measure IP through an in vitro study and to determine the IP required for strong extension of the gastric wall through an in vivo study. The time of strong gastric wall extension was defined as the time when the gastric wall was sufficiently extended by insufflated air to the extent that the folds in the greater curvature of the gastric corpus were flattened during an upper gastrointestinal endoscopy. The measurement was performed using the method developed in the in vitro study.

\section{Methods}

\section{Part 1: Development of a method to measure intragastric pressure: an in vitro study}

A rubber balloon was attached to the tip of an endoscope, and the balloon was inflated using a cuff pressure manometer ( $\triangleright$ Fig. 1). After setting the pressure, the following experiments

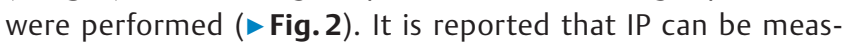
ured using an endoscope in which the probe was inserted into the forceps channel and advanced out of the tip of the endoscope [4]. However, it takes time and additional effort to insert the pressure measurement probe into the forceps channel during endoscopic examination. To enable the measurement to be easily performed in a shorter time, the tube of the pressure measurement device was directly connected to the forceps channel hole instead of inserting the probe into the forceps channel ( $\mathbf{F i g . 2}$ ). The pressure was measured using a pressure transducer AP-100 (Asahi Biomed Co. Ltd, Tokyo, Japan) connected to the forceps hole of the endoscope.

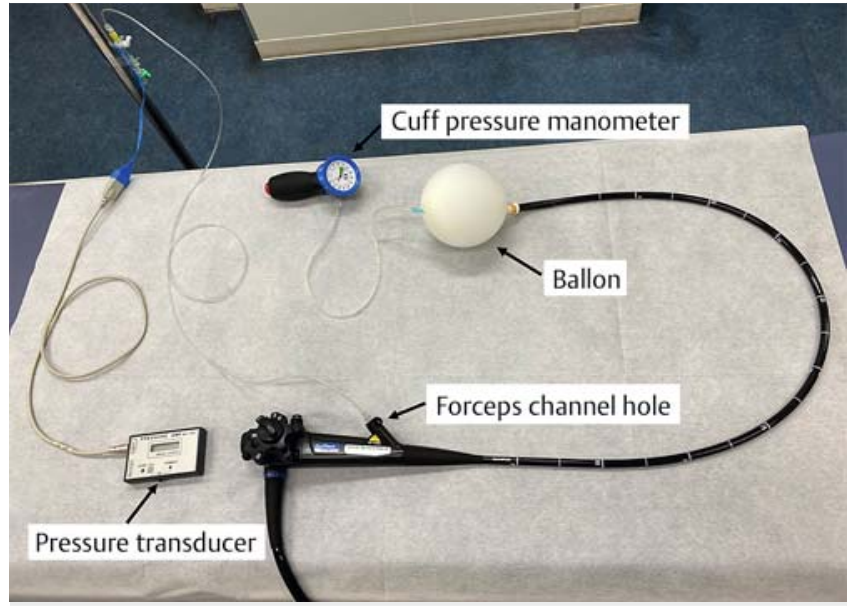

- Fig. 2 The tube in the pressure measurement device was directly connected to the forceps channel hole and measurement was performed under each experimental condition. The pressure in the balloon attached to the endoscope tip was measured using the pressure measurement device in which the tube of the pressure transducer was attached to the forceps channel of the endoscope.

To apply this method in vivo, the following points are to be considered. In actual endoscopic examination, gastric juice with mucus and bubbles are aspirated from the forceps channel before starting the observation in order to optimize the examination. Therefore, if mucus is retained in the forceps channel of the endoscope, accurate measurement of IP may be difficult. Therefore, we injected $2 \%$ lidocaine jelly (Xylocaine Jelly: Aspen Japan, Tokyo, Japan) as a substitute for mucus, into the forceps channel of the endoscope. Thereafter, we performed an in vitro study under the following conditions in order to explore the most accurate method to measure the IP.

Experiment 1: The measurement was performed under a condition in which nothing was injected into the forceps channel.

Experiment 2: The measurement was performed under a condition in which lidocaine jelly was injected into the forceps channel.

Experiment 3: The measurement was performed under a condition in which lidocaine jelly was injected into the forceps channel and then $20 \mathrm{~mL}$ of tap water was injected once for irrigation.

Experiment 4: The measurement was performed under a condition in which lidocaine jelly was injected into the forceps channel and then $20 \mathrm{~mL}$ of tap water was injected once for irrigation; the tap water retained in the forceps channel was aspirated for $10 \mathrm{sec}$ for further irrigation.

Each measurement was performed as follows. The intraballoon pressure was measured for $5 \mathrm{sec}$ with a recording interval of $0.5 \mathrm{sec}$, and the mean pressure was calculated. The intraballoon pressure at the tip of the endoscope was set at $10 \mathrm{mmHg}$, $20 \mathrm{mmHg}, 30 \mathrm{mmHg}$, and $40 \mathrm{mmHg}$ using a cuff pressure manometer ( $\triangleright$ Fig. 1 ). The pressure measurement using the endoscope channel was performed 10 times under each condition, and the mean pressure was calculated. In order to ensure the 
accuracy and precision of the method to measure IP, the mean, standard deviation, absolute and relative errors, and coefficient of variation in pressures under each condition were calculated.

Absolute error $=\mid$ true value - measured value $\mid$

Relative error $=\mid$ true value - measured value $\mid$ / true value

Coefficient of variation $=$ standard deviation/average value

\section{Endoscopes}

We used an electronic endoscopy system (EVIS LUCERA ELITE; Olympus Co., Tokyo, Japan) with high-resolution endoscopy (GIF-H290Z; Olympus) for the experiments.

Part 2: Measurement of intragastric pressure during strong extension of the gastric wall: an in vivo study

\section{Patients}

This study was approved by the Institutional Review Board of the Tobata Kyoritsu Hospital and was registered with the clinical trials registry (UMIN 000035500). All participating patients were explained about the study, and they provided written informed consent.

Consecutive patients scheduled for upper gastrointestinal endoscopy in the Department of Gastroenterology in Tobata Kyoritsu Hospital from January to March in 2019 were included in this study. Eligible patients were those who met all the following inclusion criteria and did not have any of the following exclusion criteria.

Inclusion criteria

1. Patients scheduled to undergo upper gastrointestinal endoscopy.

2. Patients with an Eastern Cooperative Oncology Group performance status score of 0 or 1 [5].

3. Patients with an age at registration $\leq 20$ years.

4. Patients who provided written informed consent for study participation.

Exclusion criteria

1. Patients at risk of upper gastrointestinal bleeding.

2. Patients with previous gastric surgery and those with a gastric tube.

3. Patients with a serious underlying disease such as heart failure and ischemic stroke were excluded.

4. Patients who would have difficulty participating in this study due to psychiatric disorders or symptoms.

5. Patients deemed ineligible for participation by the investigator or associate investigator.

\section{Endoscopic procedures for measurement of intragastric pressure}

All endoscopic procedures were performed using an electronic endoscopy system (EVIS LUCERA ELITE; Olympus Co., Tokyo, Japan) with high-resolution endoscopy (GIF-Q260, GIF-H260Z, GIF-H290Z; Olympus Co.) by certified specialists in gastrointestinal endoscopy (certified by the Japanese Gastroenterological Endoscopy Society) or an equally qualified endoscopist with > 10 years of experience in endoscopy.

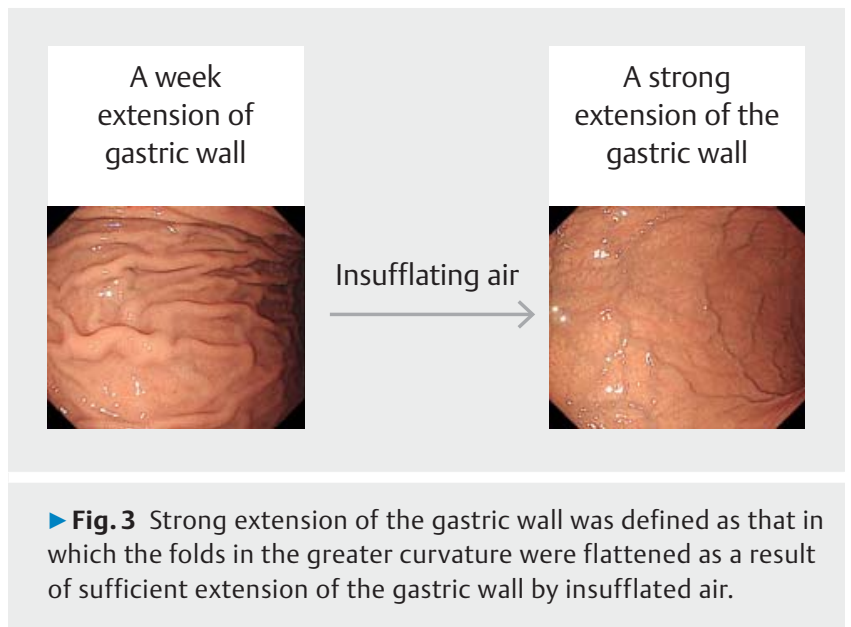

All patients underwent optimum preparation and were required to drink a mixture of mucolytic and defoaming agents in water 30 minutes before the procedures [1]. The formula comprised 20,000 U pronase (Kaken Pharmaceutical, Tokyo, Japan), $1 \mathrm{~g}$ sodium bicarbonate, and $10 \mathrm{~mL}$ dimethylpolysiloxane $(20 \mathrm{mg} / \mathrm{mL}$; Horii Pharmaceutical, Osaka, Japan) added into $100 \mathrm{~mL}$ of water. Most patients $(88 \%$, 45/51) were sedated with 3 to $10 \mathrm{mg}$ of diazepam $(5 \mathrm{mg} / \mathrm{mL}$; Takeda Pharmaceutical, Tokyo, Japan) or 2 to $8 \mathrm{mg}$ of midazolam ( $5 \mathrm{mg} / \mathrm{mL}$; SANDOZ, Tokyo, Japan) injected intravenously.

After completing the original indications for endoscopic examination, such as screening endoscopy or preoperative endoscopic assessment of early gastric cancer, we performed the following experiments specialized for this study. Air was insufflated until the gastric wall was strongly extended. Strong extension of the gastric wall was defined as that in which the greater curvature folds were flattened as a result of sufficient gastric wall extension by insufflated air ( $\mathbf{F i g . 3}$ ).

The intragastric pressure at the time of strong gastric wall extension was measured using the method developed in Part 1 (the in vitro study). $\mathrm{CO}_{2}$ was used for insufflation [6]. If adverse events including abdominal pain, Mallory-Weiss syndrome, and mucosal injury occurred during the experiments, the examination was immediately discontinued. After finishing the entire procedure, patients were asked whether they felt abdominal pain or discomfort.

\section{Endpoints}

Primary endpoint

The primary endpoint of this study was determination of the IP at the time of strong extension of the gastric wall.

\section{Secondary endpoints}

There were several secondary endpoints evaluated in this study. First was the comparison of the IP at the time of strong extension of the gastric wall between patients with non-atrophic mucosa and those with atrophic mucosa on endoscopy $[7,8]$. Second was the comparison of the IP at the time of strong extension of the gastric wall between patients with obesity (body mass index $[\mathrm{BMI}] \geq 25 \mathrm{~kg} / \mathrm{m}^{2}$ ) and those without obesity 
- Table 1 Experiment 1: Pressure management in the forceps channel without any injection.

\begin{tabular}{|l|l|l|l|l|}
\hline $\begin{array}{l}\text { Pressure in the } \\
\text { balloon }\end{array}$ & Mean \pm SD & AE & RE & CV \\
\hline $\mathbf{( m m H g )}$ & $\mathbf{( m m H g )}$ & $\mathbf{( m m H g )}$ & $\mathbf{( \% )}$ & $\mathbf{( \% )}$ \\
\hline 10 & $10.4 \pm 0.2$ & 0.2 & 2.1 & 2.2 \\
\hline 20 & $20.4 \pm 0.1$ & 0.4 & 1.9 & 0.6 \\
\hline 30 & $30.1 \pm 0.1$ & 0.1 & 1.1 & 0.4 \\
\hline 40 & $40.2 \pm 0.2$ & 0.2 & 0.5 & 0.5 \\
\hline
\end{tabular}

$\mathrm{SD}$, standard deviation; $\mathrm{AE}$, absolute error; $\mathrm{RE}$, relative error; $\mathrm{CV}$, coefficient of variation.

- Table 2 Experiment 2: Pressure management after injecting the forceps channel with lidocaine jelly.

\begin{tabular}{|l|l|l|l|l|}
\hline $\begin{array}{l}\text { Pressure in the } \\
\text { balloon }\end{array}$ & Mean \pm SD & AE & RE & CV \\
\hline $\mathbf{( m m H g )}$ & $\mathbf{( m m H g )}$ & $\mathbf{( m m H g )}$ & $\mathbf{( \% )}$ & $\mathbf{( \% )}$ \\
\hline 10 & $20,4 \pm 8.9$ & 9.4 & 93.9 & 43.5 \\
\hline 20 & $29.3 \pm 3.5$ & 9.3 & 46.5 & 11.8 \\
\hline 30 & $35.4 \pm 4.7$ & 6.1 & 20.4 & 13.2 \\
\hline 40 & $23.9 \pm 8.9$ & 11.6 & 29 & 30.9 \\
\hline
\end{tabular}

SD, standard deviation; AE, absolute error; RE, relative error; CV, coefficient of variation.

$\left(\mathrm{BMI}<25 \mathrm{~kg} / \mathrm{m}^{2}\right)$ [9]. Finally, the safety was assessed by evaluating the frequency of adverse events (AEs). AEs included abdominal pain, Mallory-Weiss syndrome, and gastric fissures. Abdominal pain severity was graded using a numerical rating scale (NRS) from 0 to 10 (0, no pain; 10, worst imaginable pain) [10].

\section{Statistical analysis}

The mean values were compared using Student's $t$-test. $P<0.05$ were considered statistically significant. SPSS version 21 J for Windows (SPSS, Chicago, Illinois, United States) was used for all statistical analyses.

\section{Results}

\section{Part 1: Development of a method to measure intragastric pressure: an in vitro study}

The standard deviation, absolute error, relative error, and coefficient of variation of pressures are demonstrated in $>$ Table 1 , - Table 2, Table 3, and - Table4. These values were high in Experiment 2 ( $\triangleright$ Table 2 ) and Experiment 3 ( $\triangleright$ Table 3 ), and they were higher than those in Experiment 1 (without any injection) ( $>$ Table 1). Conversely, the mean pressures in Experiment 4 ( $\triangleright$ Table 4) were similar to the intraballoon pressures that had been set, and the standard deviation, absolute error, relative error, and coefficient of variation were low. Thus, the measurements in Experiment 4 had high accuracy and reproducibility
- Table 3 Experiment 3: Pressure management after injecting the forceps channel with lidocaine jelly, injecting $20 \mathrm{~mL}$ of tap water once, and washing the forceps hole.

\begin{tabular}{|l|l|l|r|r|}
\hline $\begin{array}{l}\text { Pressure in the } \\
\text { balloon }\end{array}$ & Mean \pm SD & AE & RE & CV \\
\hline $\mathbf{m m H g}$ & $\mathbf{( m m H g )}$ & $\mathbf{( m m H g )}$ & $\mathbf{( \% )}$ & $\mathbf{( \% )}$ \\
\hline 10 & $12.1 \pm 4.7$ & 3.6 & 35.6 & 38.5 \\
\hline 20 & $21.1 \pm 2.4$ & 1.9 & 9.3 & 11.3 \\
\hline 30 & $26.5 \pm 4.3$ & 4.9 & 16.3 & 16.3 \\
\hline 40 & $37.9 \pm 5.1$ & 3.9 & 9.8 & 13.3 \\
\hline
\end{tabular}

$\mathrm{SD}$, standard deviation; $\mathrm{AE}$, absolute error; RE, relative error; CV, coefficient of variation.

- Table 4 Experiment 4: Pressure management after injecting the forceps channel with lidocaine jelly, injecting $20 \mathrm{~mL}$ of tap water once to wash the forceps channel, and suctioning tap water from the forceps channel for $10 \mathrm{sec}$.

\begin{tabular}{|l|l|l|l|l|}
\hline $\begin{array}{l}\text { Pressure in the } \\
\text { balloon }\end{array}$ & Mean \pm SD & AE & RE & CV \\
\hline $\mathbf{m m H g})$ & $\mathbf{( m m H g )}$ & $\mathbf{( m m H g )}$ & $\mathbf{( \% )}$ & $\mathbf{( \% )}$ \\
\hline 10 & $10.3 \pm 0.4$ & 0.4 & 3.9 & 4.3 \\
\hline 20 & $20.2 \pm 0.3$ & 0.2 & 1.2 & 1.2 \\
\hline 30 & $30.1 \pm 0.3$ & 0.3 & 0.8 & 0.9 \\
\hline 40 & $39.9 \pm 0.1$ & 0.1 & 0.3 & 0.2 \\
\hline
\end{tabular}

$\mathrm{SD}$, standard deviation; $\mathrm{AE}$, absolute error; RE, relative error; CV, coefficient of variation.

that were comparable to those in Experiment 1 in which nothing was injected into the forceps channel.

Part 2: Measurement of intragastric pressure during strong extension of the gastric wall: an in vivo study

\section{Clinical characteristics}

Fifty-four consecutive patients undergoing upper gastrointestinal endoscopy were included in this study. Of them, three patients were excluded because of difficulty retaining air in the stomach; the remaining 51 patients were included in the analysis. Overall, 31 (61\%) patients were men and the mean age \pm standard deviation (SD) was $64.7 \pm 20.3$ years, while the mean $\mathrm{BMI} \pm \mathrm{SD}$ was $23.3 \pm 3.9$ ( $>$ Table 5). Atrophic changes were observed in 37 patients (73\%) ( Table 5$)[7,8]$.

\section{Primary endpoint}

The mean IP \pm SD at the time of strong extension of the gastric wall was $14.7 \pm 3.6 \mathrm{mmHg}$. The frequency of strong extension of the gastric wall under the condition of the IP of $20 \mathrm{mmHg}$ or lower was 96\% (49/51) (> Fig.4). 
- Table 5 Clinical characteristics of 51 patients included in this study.

\begin{tabular}{|l|c|}
\hline Mean age \pm SD, (years) & $64.7 \pm 20.3$ \\
\hline Sex & \\
\hline Male (\%) & $31(61 \%)$ \\
\hline Female (\%) & $20(39 \%)$ \\
\hline Mean body mass index \pm SD, (kg/m²) & $23.3 \pm 3.89$ \\
\hline Endoscopic gastric mucosal atrophy & \\
\hline Positive (\%) & $37(73 \%)$ \\
\hline Negative (\%) & $14(27 \%)$ \\
\hline Numeric rating scale & \\
\hline 0 (\%) & $44(86 \%)$ \\
\hline $1-2(\%)$ & $7(14 \%)$ \\
\hline $3-10$ (\%) & $0(0 \%)$ \\
\hline $3-10$ (\%) & $0(0 \%)$ \\
\hline Indications for endoscopy & $12(24 \%)$ \\
\hline Screening endoscopy & $12(24 \%)$ \\
\hline Abdominal pain & $1(2 \%)$ \\
\hline Appetite loss & $5(10 \%)$ \\
\hline Preoperative assessment for gastric cancer & $14 \%)$ \\
\hline Surveillance after ESD for upper Gl cancer & \\
\hline Gastroduodenal ulcer & \\
\hline SD, standard deviation; ESD, endoscopic submucosal dissection; Gl, gastro- \\
\hline intestinal. & \\
\hline
\end{tabular}

\section{Secondary endpoints}

The mean IP \pm SD at the time of strong extension of the gastric wall in patients without atrophic mucosa on endoscopy was $14.6 \pm 3.5 \mathrm{mmHg}$ and that in those with atrophic mucosa on endoscopy was $15.0 \pm 3.5 \mathrm{mmHg}$, with no statistically significant difference between the two groups $(P=0.75)$. The mean IP \pm SD at the time of strong extension of the gastric wall in patients with a $\mathrm{BMI} \geq 25 \mathrm{~kg} / \mathrm{m}^{2}(\mathrm{~N}=11)$ was $17.8 \pm 3.7 \mathrm{mmHg}$ and that in those with a $\mathrm{BMI}<25 \mathrm{~kg} / \mathrm{m}^{2}(\mathrm{~N}=40)$ was $13.9 \pm 3.0 \mathrm{mmHg}$. Patients with obesity required significantly higher pressure to obtain strong extension of the gastric wall compared to those without obesity $(P=0.007)$ ( $P$ Fig.5). There were no serious AEs leading to discontinuation of the examination. Mild abdominal pain during the examination was observed in seven patients (13.7\%) (- Table 5).

\section{Discussion}

In this study, the results suggested that an accurate and reproducible measurement of IP can be achieved by eliminating the influence mucus. Specifically, $20 \mathrm{~mL}$ of tap water was injected into the forceps channel of the endoscope for irrigation and was aspirated for 10 seconds; thereafter, the IP was measured. We aimed to develop an easy and accurate method to measure IP using endoscopy and to determine the IP required for strong extension of the gastric wall. During upper gastrointestinal endoscopy, blind spots can be avoided by sufficient extension of the gastric wall by air insufflation, which enables the observation of subtle changes in the color and surface (elevated or depressed lesions) of lesions [1]. In particular, strong extension of the gastric wall is essential to detect lesions in the folds. Therefore, observation at the time of strong extension of the

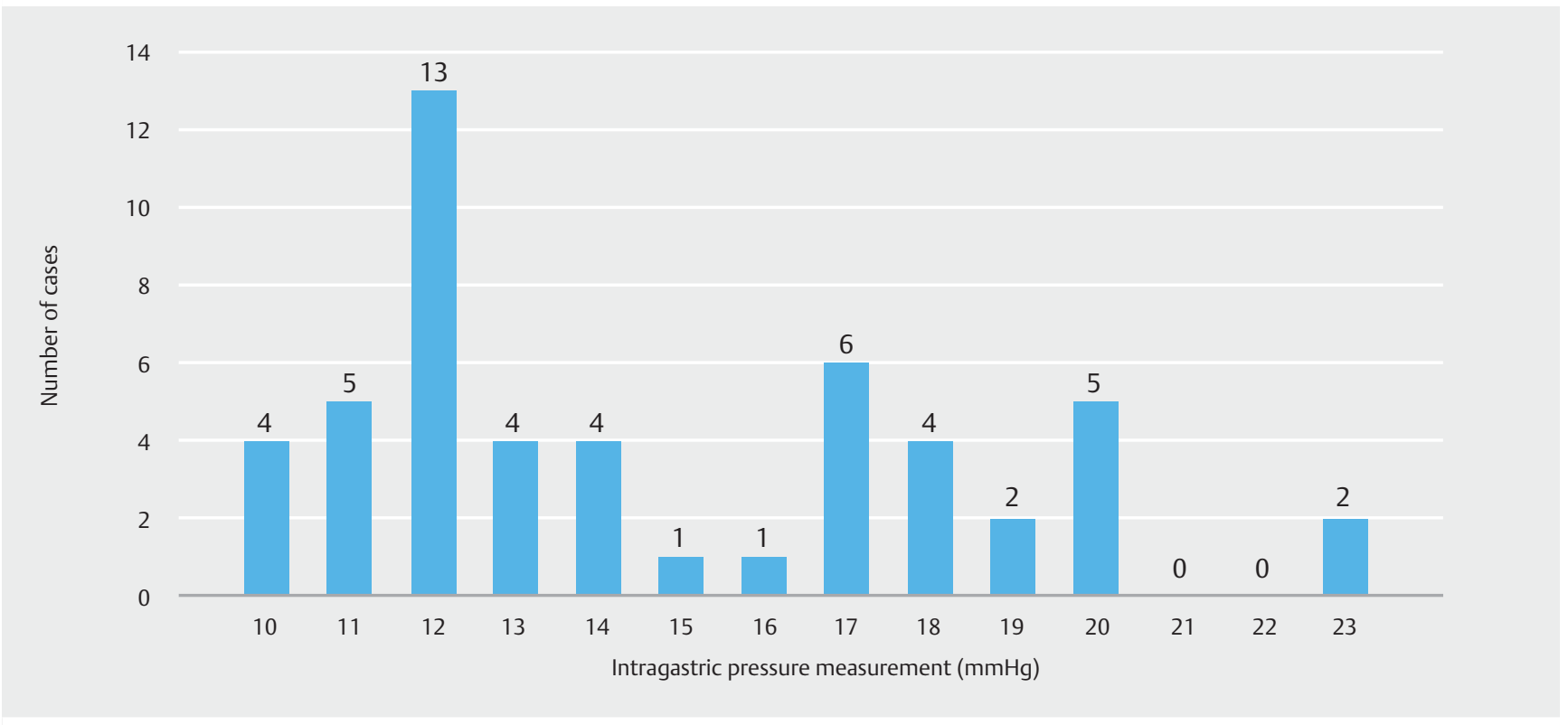

Fig. 4 Histogram of the measured intragastric pressure. Strong extension of the gastric wall occurred in $96 \%$ of participants (49/51) when the gastric pressure was at most $20 \mathrm{mmHg}$. 


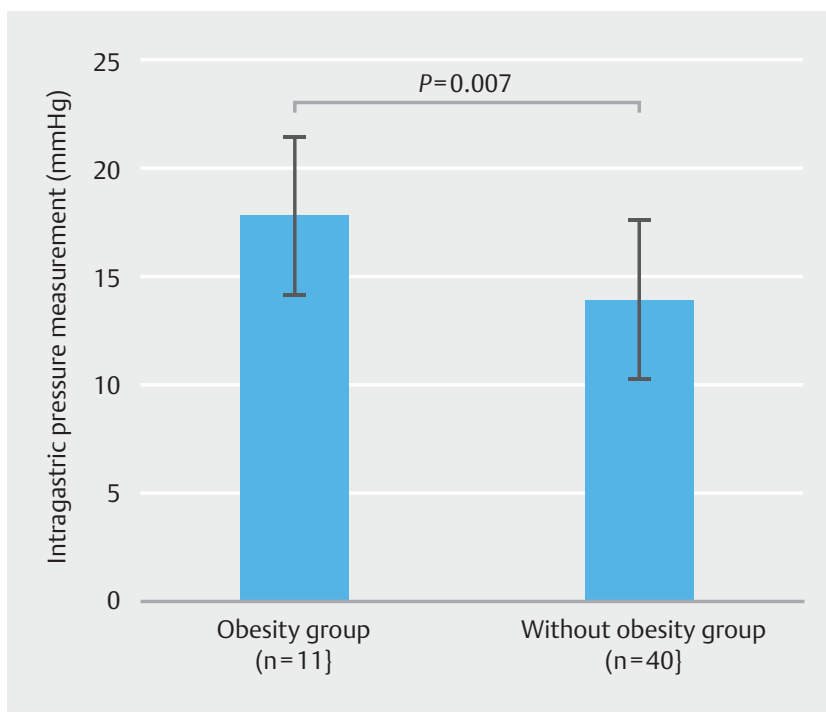

- Fig. 5 Comparison of intragastric pressure at the time of strong gastric wall extension between patients with obesity (body mass index $[\mathrm{BMI}] \geq 25 \mathrm{~kg} / \mathrm{m}^{2}$ ) and those without obesity $(\mathrm{BMI}<25 \mathrm{~kg} /$ $\mathrm{m}^{2}$ ). Patients with obesity required significantly higher pressure to obtain strong extension of the gastric wall compared to those without obesity ( $P=0.007$, Student's $t$-test).

gastric wall under certain conditions is important to establish the standard observation method. However, an objective method of measuring IP has not been established. Carbone et al. [4] and Suzuki et al. [11] reported methods to measure IP using a probe. In their studies, the probe was inserted from the forceps channel, and the IP was measured using a probe on the tip of the endoscope. However, it takes additional effort to apply this method during endoscopic examination. Therefore, we developed a simple and accurate method to measure intragastric pressure through an in vitro study. In our method, instead of inserting a probe from the forceps channel, the tube of the pressure measurement device was directly attached to the forceps channel hole. However, if this method is used in upper gastrointestinal endoscopy in clinical practice, the attachment of mucus to the forceps channel prevents accurate measurement of the intragastric pressure because mucus intervenes between the IP measurement instrument and intragastric space by occluding the channel. There is a concern that retention of aspirated mucus in the forceps channel may prevent accurate measurement of IP. Therefore, we explored the optimal condition for measuring IP through experiments under various conditions.

Subsequently, we investigated the optimal IP for strong extension of the gastric wall in patients. The mean IP \pm SD at the time of strong extension of the gastric wall was $14.7 \pm 3.6$ $\mathrm{mmHg}(10-23)$. Strong extension of the gastric wall occurred in $96 \%$ of patients $(49 / 51)$ when the IP was at most $20 \mathrm{mmHg}$ ( $\vee$ Fig.4). These results suggest that the strong extension of the gastric wall can be obtained in almost all patients when the IP is at most $20 \mathrm{mmHg}$ during upper gastrointestinal endoscopy.

Further studies regarding the usefulness and safety of the present method (IP of $20 \mathrm{mmHg}$ ) are required for clinical appli- cation. Regarding safety, Suzuki et al. [11] studied the changes induced by gastric stimulation using air inflation during endoscopy. They measured the IP at the visceral perception threshold in patients with functional dyspepsia/regurgitation esophagitis and controls and reported that visceral perception was observed in all groups when the IP was at least $22 \mathrm{mmHg}$. Additionally, incidents due to air inflation were not recorded. In the present study as well, there were no incidents or patients who complained of strong visceral perception ( $>$ Table 5). However, no studies have investigated the safety of the measurement method in which the IP was maintained at $20 \mathrm{mmHg}$ in patients undergoing endoscopy. We plan to conduct a prospective study on the safety of this method in which the IP is maintained at 20 $\mathrm{mmHg}$ (UMIN000039105). We previously reported that the non-extension sign with strong extension of the gastric wall was useful not only for endoscopic screening but also for preoperative endoscopic diagnosis of invasion depth of early gastric cancer [2,3]. In the future, we plan to conduct a prospective study on the optimal IP needed to detect the non-extension sign that is useful for the diagnosis of invasion depth in patients with early gastric cancer.

In the present study, the mean IP \pm SD in patients with nonatrophic mucosa on endoscopy did not significantly differ from that in those with atrophic mucosa on endoscopy. The mechanism of dilatation of the stomach is considered as follows. In general, the stomach is dilated by release of relaxing substances such as nitric oxide and vasoactive intestinal peptide induced by physical stimulation (extension stimulation) associated with food intake $[12,13]$. In this study, it was considered that dilatation of the stomach was related to a gastric accommodation response associated with gastric wall extension by air insufflation; therefore, it was suggested that the presence or absence of atrophic mucosa might not have influenced the mechanism driving the dilatation of the stomach. Additionally, we compared the IP at the time of strong extension of the gastric wall between patients with and without obesity (BMI $\geq 25 \mathrm{~kg} / \mathrm{m}^{2}$ vs. $<25 \mathrm{~kg} / \mathrm{m}^{2}$ ) [9]. In the present study, the IP required for extension of the stomach was significantly higher in patients with obesity than in those without obesity $(P=0.007)$ ( $\vee$ Fig.5). The potential reasons for this finding are as follows. First, as reported by Lambert et al. [14], obesity is associated with increased intraperitoneal pressure, suggesting that the pressure required for extension of the gastric wall is greater in patients with obesity because of their higher intraperitoneal pressure. Second, in this study, dilatation of the stomach was related to a gastric accommodation response, which was associated with gastric wall extension by air insufflation as described above. Weisen et al. reported that the autonomic responsiveness of the stomach was decreased in patients with obesity [15]. Therefore, it is suggested that the magnitude of stimulation required for strong extension of the gastric wall is greater in patients with obesity than in those without obesity.

The limitation of the in vitro experiment was that we did not perform a distribution-free test and calculated the standard deviation, absolute error, relative error, and coefficient of variation. Ten measurements may have been somewhat small for an accurate measurement. The limitation of the in vivo study 
was that it was an exploratory study of a small number of patients at a single center. With respect to the comparison of IP at the time of strong gastric wall extension between patients with endoscopic non-atrophic mucosa and those with endoscopic atrophic mucosa and between obese and non-obese patients as described in the secondary end-points, more number of cases are needed because the influence of other factors could not be excluded due to the small sample size. In addition, with respect to adverse events at the time of strong gastric wall extension, more cases are needed due to the small sample size. We are now planning to perform a clinical trial in a multicenter setting including a large number of patients.

\section{Conclusion}

In this study we developed an accurate, and reproducible method of measuring IP under the following conditions. To eliminate the factors that may negatively affect the accuracy of measurement (such as mucus in the forceps channel), $20 \mathrm{~mL}$ of tap water was injected into the forceps channel for irrigation and the tap water in the forceps channel was aspirated for $10 \mathrm{sec}$. Thereafter, the IP was measured. Our study also showed that strong extension of the gastric wall can be obtained in almost all patients when an IP of $20 \mathrm{mmHg}$ is applied during upper gastrointestinal endoscopy. The quantitative measurement of IP may be useful for standardizing upper gastrointestinal endoscopy procedures, both for screening and for preoperative diagnosis of invasion depth of early gastric cancer.

\section{Acknowledgments}

The authors thank Dr. Eikichi Ihara (Department of Medicine and Bioregulatory Science, Graduate School of Medical Sciences, Kyushu University) for his constructive discussion and Dr. Hisatomi Arima (Department of Preventive Medicine and Public Health, Fukuoka University, Fukuoka, Japan) for his constructive discussion regarding statistical analysis.

\section{Competing interests}

The authors declare that they have no conflict of interest.
References

[1] Yao K. The endoscopic diagnosis of early gastric cancer. Ann Gastroenterol 2013; 26: 11-22

[2] Yao T, Tanabe H, Nagahama T et al. Clinicopathological study for accurate endoscopic diagnosis of submucosal invasion by early gastric cancer of depressed type (in Japanese, with English abstract). Stomach Intest (Tokyo) 2008; 43: 1109-1125

[3] Nagahama T, Yao K, Imamura K et al. Diagnostic performance of conventional endoscopy? in the identification of submucosal invasion by early gastric cancer: the "non-extension sign" as a simple diagnostic marker Gastric Cancer 2017; 20: 304-313

[4] Carbon F, Tack J, Hoffman I. The intragastric pressure measurement: a novel method to assess gastric accommodation in functional dyspepsia children. J Pediatr Gastroenterol Nutr 2017; 64: 918-924

[5] Oken MM, Creech RH, Tormey DC et al. Toxicity and response criteria of the Eastern Cooperative Oncology Group. Am J Clin Oncol 1982; 5: 649-655

[6] Mori H, Kobara H, Muramatsu A et al. Comparison of postoperative complications after endoscopic submucosal dissection: differences of insufflations and anesthesias. Diagn Ther Endosc 2011: doi:10.1155/ 2011/709237

[7] Kimura K, Takemoto T. An endoscopic recognition of the atrophic border and its significance in chronic gastritis. Endoscopy 1969; 1: 87-97

[8] Sakaki N, Momma K, Egawa N et al. The influence of Helicobacter pylori infection on the progression of gastric mucosal atrophy and occurrence of gastric cancer. Eur J Gastroenterol Hepatol 1995; 7 Supp. 1: S59-S62

[9] Japanese Society for the Study of Obesity. Japanese obesity treatment guideline. (in Japanese). Tokyo: Lifescience; 2016

[10] Jensen MP, Turner JA, Romano JM et al. Comparative reliability and validity of chronic pain intensity measures. Pain 1999; 83: 157-162

[11] Suzuki T, Hirano M, Yamamoto Y. Examination of visceral perception and gastric tone by gastric stimulation using air inflation during endoscopy. J Int Med Res 2005; 33: 160-169

[12] Desai KM, Sessa WC, Vane JR. Involvement of nitric oxide in the reflex relaxation of the stomach to accommodate food or fluid. Nature 1991; 351: 477-479

[13] Tack J, Demedts I, Meulemans A et al. Role of nitric oxide in the gastric accommodation reflex and in meal induced satiety in humans. Gut 2002; 51: 219-224

[14] Lambert DM, Marceau S, Forse RA. Intra-abdominal pressure in the morbidly obese. Obes Surg 2005; 15: 1225-1232

[15] Wisén O, Hellström PM. Gastrointestinal motility in obesity. J Intern Med 1995; 237: 411-418 